\title{
Increased oxidative stress and altered antioxidants status in patients with chronic allergic rhinitis
}

\author{
Shiefa Sequeira ${ }^{1}$, Ashalatha V. Rao ${ }^{2}$, Anjali Rao ${ }^{3}$ \\ ${ }^{1}$ Department of Biochemistry, SRL Diagnostics, Dubai, UAE \\ ${ }^{2}$ Department of Biochemistry, K. S. Hegde Medical Accademy, Deralakatte Mangalore, India \\ ${ }^{3}$ Department of Biochemistry, Kasturba Medical College, Manipal, India \\ Email: drshiefa31@yahoo.co.in
}

Received 8 August 2012; revised 15 September 2012; accepted 27 October 2012

\section{ABSTRACT}

Background: Allergic rhinitis is an inflammatory disorder of the upper airways. Although several oxidants and antioxidants are likely to be involved, alterations in only limited parameters have been studied. Objective: In this study an attempt has been made to study the oxidant-antioxidant imbalance by investigating changes in a wide range of oxidants and antioxidants in the blood. Methods: Blood samples were obtained from 39 chronic allergic rhinitis patients (males 24, females 15), aged 20 - 70 (mean age $36.33 \pm 2.03$ ) years and 53 individuals ( 36 males, 17 females); aged 24 to 64 (mean age $45.42 \pm 1.36$ ) years. Duration of allergic rhinitis was $1.77 \pm 0.237$ years. In the study group, nasal symptoms were scored and the results were recorded. The patients were classified as having perennial Allergic rhinitis (PAR) if they had had at least 2 rhinitis symptoms (sneezing, rhinorrhea, nasal obstruction, itching) for at least 6 months a year in the previous 2 years and if they had a positive skin prick test response to at least 1 clinically significant perennial allergen (e.g., house dust mites, molds, cockroach, cockroach excrement grass and tree pollen, cat and dog epithelia and molds, or animal dander). They had no other allergic diseases except persistent allergic rhinitis diagnosed by the physical and history examination. Erythrocyte lipid peroxidation, erythrocyte antioxidants viz., glutathione, glutathione reductase, superoxide dismutase, catalase and plasma antioxidants viz., ceruloplasmin, glutathione-S-transferase, vitamin C, total antioxidant activity were estimated in the above two groups. Results: Erythrocyte lipid peroxidation $(0$ hour, $p<0.01)$ and superoxide dismutase $(p<0.01)$ were significantly higher, whereas plasma vitamin $C(p<0.001)$, ceruloplasmin $(p<0.05)$ and total antioxidant activity $(p<0.001)$ were significantly lower in chronic allergic rhinitis patients when compared to controls. Plasma glutathione $S$ transferase and erythrocyte catalase, glutathione, and glutathione reductase remained unchanged from normal subjects. Conclusion: The changes in different parameters indicate an imbalance in the oxidant and antioxidant status in chronic allergic rhinitis patients. Further studies are required to investigate the potential for antioxidant supplements to be used as routine therapy in chronic allergic rhinitis patients. Capsule Summary: The study shows that the body is trying to cope for the oxidative stress by altering the enzyme levels. But external supplement may also be required as the total antioxidant levels are very much depleted.

Keywords: Oxidative Stress; Antioxidant Status; Chronic Allergic Rhinitis

\section{INTRODUCTION}

Allergic rhinitis represents a global health issue affecting between $10 \%$ and $20 \%$ of the world population, with increasing prevalence over the last decade [1]. It is a very common disorder affecting people at all ages and has been associated with significant impairments in quality of life, sleep and work performance [2]. AR is a complex disease characterized by inflammation of the nasal mucosa, along with paroxysms of sneezing, itching of the eyes, nose and palate, rhinnorhea and nasal obstruction [3]. In allergic rhinitis, numerous inflammatory cells, including mast cells, CD4-positive T cells, B cells, macrophages, and eosinophils, infiltrate the nasal lining upon exposure to an inciting allergen (most commonly airborne dust mite fecal particles, cockroach residues, animal dander, moulds, and pollens). The T cells infiltrating the nasal mucosa are predominantly $\mathrm{T}$ helper $(\mathrm{Th}) 2$ in nature and release cytokines (e.g., interleukin [IL]-3, IL-4, IL-5, and IL-13) that promote immunoglobulin E (IgE) production by plasma cells. IgE production, in turn, triggers the release of mediators, such as histamine and leukotrienes, that are responsible for arteriolar dilation, increased vascular permeability, itching, rhinorrhea (runny 
nose), mucous secretion, and smooth muscle contraction $[1,2]$. The mediators and cytokines released during the early phase of an immune response to an inciting allergen, trigger a further cellular inflammatory response over the next 4 to 8 hours (late-phase inflammatory response) which results in recurrent symptoms (usually nasal congestion) $[1,4]$.

ROS generation through normal cellular metabolism and by means of exogenous insults is a constant problem for which cells have developed multiple protective mechanisms to survive. For example, cigarette smoke inhalation results in increased exposure to both superoxide and hydrogen peroxide $[5,6]$. To protect itself against exposure to noxious oxidants, the airway mucosa has developed an antioxidant system. Elevated levels of ROS such as hydroxyl radicals, superoxides, and peroxides may induce a variety of pathological changes that are highly relevant in nasal and airway mucosas. These include lipid peroxidation, increased airway reactivity, increased nasal mucosal sensitivity and secretions, production of chemoattractant molecules, and increased vascular permeability. The association between chronic inflammation and oxidative stress is well documented. Oxidative stress results in an imbalance between the oxidative forces and the antioxidant defense systems, which is believed to favor an oxidative injury that has been implicated in the pathogenesis of asthma and AR $[7,8]$. In the studies carried out thus far, the investigators have studied changes in only a few parameters. The role of oxidative stress in allergic rhinitis is not well studied but is likely to be similar to that in asthma [9]. Because several oxidants and antioxidants are likely to be involved in the pathogenesis of the inflammatory process in allergic rhinitis, a comprehensive study of several parameters of oxidative stress and antioxidant defenses is required to highlight the role of oxidant-antioxidant imbalance in allergic rhinitis. The present study was carried out with this aim.

\section{MATERIALS AND METHODS}

\subsection{Study Design}

The study plan was approved by the Ethics Committee of the Medical Faculty, and all subjects volunteered for the trial. Patient group age ranged was 20 to 70 years (mean age, $36.33 \pm 2.03$ ); the control group age range was 24 to 64 years (mean age, $45.42 \pm 1.36$ ). In the patients group, 24 patients were male and 15 patients were female. In the control group, 36 patients were male and 17 patients were female. In the patients group, the mean complaint time ranged from $1.77 \pm 0.237$ year. In the study group, nasal symptoms were scored and the results were recorded. The patients were classified as having perennial Allergic rhinitis (PAR) if they had had at least 2 rhinitis symptoms (sneezing, rhinorrhea, nasal obstruction, itching) for at least 6 months a year in the previous 2 years and if they had a positive skin prick test response to at least 1 clinically significant perennial allergen (e.g., house dust mites, molds, cockroach, cockroach excrement grass and tree pollen, cat and dog epithelia and molds, or animal dander). They had no other allergic diseases except persistent allergic rhinitis diagnosed by the physical and history examination.

\subsection{Methods}

Random blood samples were collected in heparinized bottles from normal subjects and allergic rhinitis patients. The erythrocyte suspension was prepared according to the method of Kartha and Krishnamurthy [10]. Blood was centrifuged at $3000 \mathrm{~g}$ for 10 minutes. Plasma and buffy coat were carefully removed and the separated cells washed thrice with cold saline phosphate buffer, $\mathrm{pH}$ 7.4 (sodium phosphate buffer containing $0.15 \mathrm{M} \mathrm{NaCl}$ ). The RBCs were then suspended in an equal volume of physiological saline. This suspension was used for some of the assays performed. The assays performed in the erythrocytes were lipid peroxidation (LP), glutathione (GSH), glutathione reductase (GR), catalase (CT) and in plasma were glutathione-S-transferase (GST), vitamin C, ceruloplasmin, antioxidant activity (AOA).

The hemoglobin content of the erythrocytes was determined by the cyanmethemoglobin method. Erythrocyte LP was determined by incubating RBC suspension in saline phosphate buffer containing $0.44 \mathrm{M} \mathrm{H}_{2} \mathrm{O}_{2}$ at 0 hour and 2 hours. Aliquots were drawn from the above mixture at 0 hour and 2 hours. Lipid peroxidation in RBC was determined by estimating malondialdehyde (MDA) produced using thiobarbituric acid [11]. Erythrocyte GR activity was determined by recording the decrease in absorbance due to depletion of NADPH for a period of 5 minutes at $340 \mathrm{~nm}$ [12]. SOD was determined according to the method of Beauchamp and Fridovich [13] based on inhibition of nitrozolium reduction. CT activity in the hemolysate was determined by adopting the method of Brannan et al. [14]. The assay is based on the disappearance of $\mathrm{H}_{2} \mathrm{O}_{2}$ in the presence of the enzyme source at $26^{\circ} \mathrm{C}$. The GSH content of erythrocytes was determined as described by Beutler et al. [15].

Plasma ceruloplasmin was determined by p-phenylene diamine oxidase activity [16]. Plasma vitamin C was determined chemically using dinitrophenyl hydrazine as a colour compound [17]. Plasma GST was determined by incubating CDNB (1 chloro 2,4 dinitro benzene) with reduced GSH in the presence of serum containing glutathione-S-transferase. 2,4-dinitrophenylglutathione (adduct) formed was read at $340 \mathrm{~nm}$ [18]. AOA activity was measured by Fenton type reaction [19]. The package used for statistical analysis was SPSS/PC+ (version 
11.0).

\section{RESULTS}

\subsection{Oxidative Changes}

The mean TBARS level estimated in allergic rhinitis patients was high at 0 hour and 2 hours compared to normal controls (Table 1). The susceptibility towards lipid peroxidation, indicated by the difference of the two values, obtained at 0 hour and 2 hour was also increased compared to normal controls. But only the increase observed at 0 hour was significant $(\mathrm{p}<0.01)$.

\subsection{Erythrocyte Antioxidants}

The mean SOD enzyme activity was increased significantly in the erythrocytes of patients with allergic rhinitis when compared to normal controls (NC, p < 0.01) (Table 2). No statistical significant variation in mean glutathione level, catalase activity, and glutathione reductase activity was observed in patients when compared with normal controls.

\subsection{Plasma Antioxidants}

The mean vitamin C levels decreased significantly in case of allergic rhinitis patients compared to normal controls (Table 3). There was a significant rise in mean ceruloplasmin levels in allergic rhinitis patients when com- pared to normal controls (Table 3). Mean plasma antioxidant activity in allergic rhinitis patients was significantly decreased compared to normal controls (Table 3). There was no significant change in glutathione $\mathrm{S}$ transferase activity in allergic rhinitis patients when compared to normal controls (Table 3).

\section{DISCUSSION}

Allergic rhinitis is an inflammatory disorder of the upper airways. Reactive oxygen species (free radicals and nonradicals) contribute to the pathogenesis of allergic disorders $[20,21]$. The presence of chronic inflammation in the epithelium of upper airways in allergic rhinitis, could contribute to the development of the considerable persistent oxidative stress. Airway inflammatory cells are the likely source of an increase in ROS production [21,22]. Other sources of ROS in airways include environmental sources such as $\mathrm{O}_{3}$ and hydrogen peroxide from air pollution and cigarette smoke and intracellular sources such as mitochondrial respiration, xanthine oxidase, cyt P450 and cytochrome b5 enzyme.

ROS concentrations are controlled by antioxidant scavenger systems. Antioxidants that are found in the epithelial lining fluids and epithelial cells of the airways include superoxide dismutase, glutathione peroxidase, catalase, thioredoxin, the iron-binding proteins lactoferrin and transferrin, the copper-binding protein cerulo-

Table 1. In vitro RBC lipid peroxidation in allergic rhinitis.

\begin{tabular}{|c|c|c|c|}
\hline \multirow{2}{*}{ Group } & \multicolumn{3}{|c|}{$\begin{array}{c}\text { TBARS as nmol MDA/g Hb } \\
\text { Mean } \pm \text { SEM }\end{array}$} \\
\hline & 0 Hour & 2 Hours & Susceptibility to LP \\
\hline $\begin{array}{l}\text { Normal Controls (NC) } \\
\qquad \mathrm{n}=53\end{array}$ & $\begin{array}{c}77.8 \pm 4.46 \\
(20.8-181.6)\end{array}$ & $\begin{array}{c}384.5 \pm 18.54 \\
(102.8-898.7)\end{array}$ & $\begin{array}{l}306.0 \pm 16.65 \\
(72.0-735.6)\end{array}$ \\
\hline $\begin{array}{l}\text { Allergic Rhinitis } \\
\qquad \mathrm{n}=39\end{array}$ & $\begin{array}{l}100.0 \pm 6.69^{* *} \\
(37.7-232.6)\end{array}$ & $\begin{array}{c}461.8 \pm 34.39 \\
(123.6-1002.8) \\
\text { NS }\end{array}$ & $\begin{array}{c}361.8 \pm 30.92 \\
(34.9-851.9) \\
\text { NS }\end{array}$ \\
\hline \% Change & $28.53 \%>\mathrm{NC}$ & $20.10 \%>\mathrm{NC}$ & $18.23 \%>\mathrm{NC}$ \\
\hline
\end{tabular}

Significance of results vs. NC: ${ }^{* *} \mathrm{p}<0.01$, NS = not significant; Ranges of TBARS levels observed are given in parentheses; $\mathrm{n}=$ number of cases; (Kruskal Wallis Test-Mann Whitney Test).

Table 2. Erythrocyte antioxidant levels in allergic rhinitis (Mean \pm SEM).

\begin{tabular}{|c|c|c|c|c|}
\hline Diagnosis & $\begin{array}{c}\text { GSH } \\
(\mu \mathrm{mol} / \mathrm{g} \mathrm{Hb})\end{array}$ & $\begin{array}{c}\text { SOD } \\
\text { (units/g Hb) }\end{array}$ & $\begin{array}{c}\text { Catalase } \\
\text { (units/g Hb) }\end{array}$ & $\begin{array}{c}\text { GR } \\
\text { (units/g Hb) }\end{array}$ \\
\hline Normal Controls (NC) & $\begin{array}{c}4.79 \pm 0.209 \\
(2.36-10.25) \\
n=53\end{array}$ & $\begin{array}{c}9214 \pm 492.5 \\
(4046-21,990) \\
n=53\end{array}$ & $\begin{array}{c}245,996 \pm 10410.2 \\
(27,920-413,385) \\
n=53\end{array}$ & $\begin{array}{c}1.77 \pm 0.153 \\
(0.10-4.09) \\
n=51\end{array}$ \\
\hline Allergic Rhinitis & $\begin{array}{c}5.33 \pm 0.390 \\
(0.90-10.38) \\
n=39 \\
\text { NS }\end{array}$ & $\begin{array}{c}11,367 \pm 777.9^{* *} \\
(2826-23,621) \\
n=39\end{array}$ & $\begin{array}{c}240,358 \pm 18213.4 \\
(73,886-531,720) \\
n=39 \\
N S\end{array}$ & $\begin{array}{c}1.90 \pm 0.391 \\
(0.00-12.97) \\
n=36 \\
\text { NS }\end{array}$ \\
\hline \% Change & $11.27 \%>\mathrm{NC}$ & $23.36 \%>\mathrm{NC}$ & $2.29 \%<\mathrm{NC}$ & $7.34 \%<\mathrm{NC}$ \\
\hline
\end{tabular}

Statistical significance of results vs. NC: ${ }^{* *} \mathrm{p}<0.01$, NS = not significant; The figures in the parentheses indicate the ranges of antioxidant levels observed; $\mathrm{n}=$ number of cases; (Kruskal Wallis Test-Mann Whitney Test). 
Table 3. Plasma antioxidant levels in allergic rhinitis patients (Mean \pm SEM).

\begin{tabular}{ccccc}
\hline Diagnosis & $\begin{array}{c}\text { Vitamin C } \\
(\boldsymbol{~} \mathbf{m o l} / \mathbf{L})\end{array}$ & $\begin{array}{c}\text { Ceruloplasmin } \\
\mathbf{( g / L )}\end{array}$ & $\begin{array}{c}\text { GST } \\
(\mathbf{I U} / \mathbf{L})\end{array}$ & $\begin{array}{c}\text { AOA } \\
(\mathbf{m m o l} / \mathbf{L})\end{array}$ \\
\hline \multirow{3}{*}{ Normal Controls (NC) } & $22.5 \pm 1.23$ & $0.479 \pm 0.0268$ & $4.31 \pm 0.45$ & $1.03 \pm 0.060$ \\
& $(3.5-49.5)$ & $(0.225-1.40)$ & $(0.410-15.41)$ & $(0.32-2.20)$ \\
& $\mathrm{n}=53$ & $\mathrm{n}=53$ & $\mathrm{n}=53$ & 53 \\
Allergic Rhinitis & $13.9 \pm 1.78^{* * * *} \$$ & $0.615 \pm 0.0728^{*}$ & $4.66 \pm 0.522$ & $0.61 \pm 0.042^{* * * \#}$ \\
& $(1.5-51.0)$ & $(0.112-2.310)$ & $\mathrm{n}=39$ & $(0.12-1.24)$ \\
\% Change & $\mathrm{n}=39$ & $\mathrm{n}=39$ & $\mathrm{n}=36$ & $40.70 \%<\mathrm{NC}$ \\
\hline
\end{tabular}

Statistical significance of results vs. NC: ${ }^{*} \mathrm{p}<0.05,{ }^{* *} \mathrm{p}<0.01,{ }^{* * *} \mathrm{p}<0.001$, NS = not significant; The figures in the parentheses indicate the ranges of antioxidant levels observed; $\mathrm{n}=$ number of cases; ( $\$$ = ANOVA- Dunnttt $\mathrm{t}$ Test, ${ }^{\#}=$ Kruskal Wallis Test-Mann Whitney Test).

plasmin, and the low-molecular-weight antioxidants, like glutathione, vitamin C, urate, and vitamin E [21-23].

SOD is an enzyme that provides an initial defense against oxidative insults. They convert extremely reactive superoxide radicals to potentially toxic hydrogen peroxide, which in turn is metabolized by catalase and glutathione peroxidase. $\mathrm{Cu}, \mathrm{Zn}$-SOD activity has been shown to be reduced in the epithelial lining fluid $[24,25]$ and in bronchial epithelial cells $[25,26]$ of patients with asthma. Otto-Knapp et al. [27] found increased activities of SOD and glutathione peroxidase after ozone exposure in cultured human nasal mucosa. However, SOD levels in the upper airways in patients with allergic rhinitis are still undefined. In the present study, an increase in the SOD enzyme activity in the erythrocytes was observed in the allergic rhinitis patients. Interestingly, although SOD, a specific inhibitor of oxygen radicals, was increased in our study catalase did not rise. This imbalance of SOD/ CAT in the erythrocytes also equally explains oxidative stress in AR patients. A rise in lipid peroxidation levels measured as erythrocyte TBARS also explains oxidative stess in AR patients showing the important significance of the oxidative damage caused by imbalance in antioxidant functions. Higher levels found in erythrocytes could be because of the fact that, erythrocytes are very susceptible to oxidative damage due to high degree of polyunsaturated fatty acids in their membranes, and high concentration of intracellular oxygen and hemoglobin whose redox chemistry is known to produce oxyradicals [28]. Studies done by Mates J. et al. in erythrocytes of allergic rhinitis patients after exposure to pollen and house dust mite also revealed an increase in erythrocyte SOD and lipid peroxidation [29].

Ascorbic acid is an antioxidant vitamin which is physiologically available in respiratory tracts. As an antioxidant, it may cause a reduction of negative effects caused by oxidative attack on tissues during inflammation. Smoking is known to increase the metabolic turnover of ascorbic acid due to its oxidation by free radicals and ROS generated by cigarette smoking. Ascorbic acid has been shown to stimulate immune system by enhancing
T-cell proliferation in response to infection. These cells are capable of lysing infected targets by producing large quantities of cytokines and by helping B-cells to synthesize immunoglobulins to control inflammation reaction. Plasma devoid of vitamin $\mathrm{C}$ has increased rate of lipid peroxidation. On the contrary, plasma in the presence of vitamin $\mathrm{C}$ has decreased rate lipid peroxidation. This indicates that vitamin $\mathrm{C}$ is an important antioxidant in the plasma. Oxidative stress in allergic rhinitis patients caused by increased oxygen free radicals might have increased consumption of vitamin $\mathrm{C}$ to mitigate the toxicity of free radicals. This in turn, might have resulted in decreased plasma vitamin $\mathrm{C}$ level. Thus, a deficiency of plasma vitamin $\mathrm{C}$ level must have increased the susceptibility of RBC towards lipid peroxidation in allergic rhinitis patients. In another study on children with asthma, it was shown that the reduction in vitamin $\mathrm{C}$ causes and increases the risk of asthma. Kalaycı et al. [30] showed that children with asthma had lower level of ascorbic acid when comparing with healthy children in the cycle of remission. In our study, a significant decrease has been observed in the plasma vitamin $\mathrm{C}$ and total antioxidant level between the AR and control groups. Podoshin et al. [31] showed that vitamin $\mathrm{C}$ reinforcement reduced the symptoms in $74 \%$. A diet rich in antioxidants has been associated with a low prevalence of allergic disease [32].

Ceruloplasmin levels, in the present study, have significantly increased in patients suffering from allergic rhinitis. It is an acute phase protein and also has antioxidant activity. Ceruloplasmin catalyzes oxidation of ferrous ions and does not release any damaging oxygen radicals. The ferroxidase activity of ceruloplasmin allows it to inhibit iron dependent lipid peroxidation or $\mathrm{OH} \cdot$ formation from hydrogen peroxide and superoxide ions. Since ceruloplasmin is a copper binding enzyme, it also sequesters the copper ions in the plasma and reduces its deleterious effects on RBC. The rise in ceruloplasmin in the present study may have occured in response to inflammation of airways as well as a part of an increased antioxidant response to cell injury. 
The present study is the first to examine changes in several measures of oxidative stress and antioxidant status in allergic rhinitis. Previous studies have focused on only a few parameters, but we have investigated alterations in a wide variety of antioxidants. Taken together, these results provide new information on the role of oxidative stress in allergic rhinitis. A strategy for designing well-balanced antioxidant therapies based on both reducing endogenous ROS production and increasing the total antioxidant capacity of human cells may prove useful in the prevention of allergic rhinitis.

\section{REFERENCES}

[1] Peter, S. and Harold, K. (2011) Allergic rhinitis. Allergy, Asthma \& Clinical Immunology, 7, S3.

[2] Dykewicz, M.S. and Hamilos, D.L. (2010) Rhinitis and sinusitis. Journal of Allergy and Clinical Immunology, 125, S103-S115. doi:10.1016/j.jaci.2009.12.989

[3] Marshall, P. and Martin, D.V. (2005) Allergic rhinitis. Journal of Medicine, 353, 1934-1944.

[4] Small, P., Frenkiel, S., Becker, A., Boisvert, P., Bouchard, J., Carr, S., Cockcroft, D., Denburg, J., Desrosiers, M., Gall, R., Hamid, Q., Hébert, J., Javer, A., Keith, P., Kim, H., Lavigne, F., Lemièr, C., Massoud, E., Payton, K., chellenberg, B., Sussman, G., Tannenbaum, D., Watson, W., Witterick, I. and Wright, E. (2007) The Canadian rhinitis working group: Rhinitis: A practical and comprehensive approach to assessment and therapy. Journal of Otolaryngology, 36, S5-S27. doi:10.2310/7070.2006.X002

[5] Nakayama, T., Church, D.F. and Pryor, W.A. (1989) Quantitative analysis of the hydrogen peroxide formed in aqueous cigarette tar extracts. Free Radical Biology \& Medicine, 7, 9-15. doi:10.1016/0891-5849(89)90094-4

[6] Winston, G.W., Church, D.F., Cueto, R. and Pryor, W.A. (1983) Oxygen consumption and oxyradical production from microsomal reduction of aqueous extracts of cigarette tar. Archives of Biochemistry and Biophysics, 304, 371-378. doi:10.1006/abbi.1993.1364

[7] Marple, B.F. (2010) Allergic rhinitis and infl ammatory airway disease: Interactions within the unified airspace. American Journal of Rhinology \& Allergy, 24, 249-254. doi:10.2500/ajra.2010.24.3499

[8] Ercan, H., Birben, E., Dizdar, E.A., Keskin, O., Karaaslan, C., Soyer, O.U., Dut, R., Sackesen, C., Besler, T. and Kalaycı, O. (2006) Oxidative stress and genetic and epidemiologic determinants of oxidant injury in childhood asthma. Journal of Allergy and Clinical Immunology, 118, 1097-1110. doi:10.1016/j.jaci.2006.08.012

[9] Russel, P.B. and James, D.C. (2002) Oxidative stress in allergic respiratory diseases. Journal of Allergy and Clinical Immunology, 110, 349-356. doi:10.1067/mai.2002.126780

[10] Kartha, V.N. and Krishnamurthy, S. (1978) Factors affecting in vitro lipid peroxidation of rat brain homogenate. Indian Journal of Physiology \& Pharmacology, 22, 44-
52.

[11] Stocks, J. and Dormandy, T.L. (1971) The auto-oxidation of human red cell lipids induced by hydrogen peroxide. British Journal of Haematology, 20, 95-111. doi:10.1111/j.1365-2141.1971.tb00790.x

[12] Horn, H.D. and Burns, F.H. (1978) Glutathione reductase. In: Bergmeyer, H.V., Ed., Methods of Enzymatic Analysis, Academic Press, NewYork, 875.

[13] Beauchamp, C. and Fridrovich, I. (1971) Superoxide dismutase: Improved assays and an assay applicable to acrylamide gels. Analytical Biochemistry, 44, 276-287. doi:10.1016/0003-2697(71)90370-8

[14] Brannan, T.S., Maker, H.S. and Raes, I.P. (1989) Regional distribution of catalase in the adult rat brain. Journal of Neurochemistry, 36, 307. doi:10.1111/j.1471-4159.1981.tb02411.x

[15] Beutler, E., Duron, O. and Kelly, B.M. (1963) Improved method for the determination of blood glutathione. Journal of Laboratory and Clinical Medicine, 61, 882.

[16] William, S.F. and Shozo, N. (1970) Measurement of serum ceruloplasmin by its p phenylenediamine oxidase activity. Clinical Chemistry, 16, 903-909.

[17] Norbert, W.T. (1986) Text book of clinical chemistry. W B Saunders Co., Orlando, 960.

[18] Adachi, Y., Horii, K., Takahashi, Y., et al. (1980) Serum glutathione-S-transferase activity in liver diseases. Clinica Chimica Acta, 106, 243-255.

[19] Koracevic, D., Koracevic, G., Djordjevic, V., et al. (2001) Method for the measurement of antioxidant activity in human fluid. Journal of Clinical Pathology, 54, 356-361. doi:10.1136/jep.54.5.356

[20] Kim, B.-J. and Hong, S.-J. (2012) Ambient air pollution and allergic diseases in children. Korean Journal of Pediatrics, 559, 185-192.

[21] Wright, D.T., Cohn, L.A., Li, H., Fisher, B., Li, C.M. and Adler, K.B. (1994) Interaction of oxygen radicals with airway epithelium. Environmental Health Perspectives, 10, 85-90.

[22] Bowler, R.P. and Crapo, J.D. (2002) Oxidative stress in allergic respiratory diseases. Journal of Allergy and Clinical Immunology, 110, 349-356. doi:10.1067/mai.2002.126780

[23] Van Der Vliet, A. and Cross, C.E. (2001) Innate antioxidant defense systems in the respiratory tract. BioFactors, 15, 83-86.

[24] Comhair, S.A., Bhathena, P.R., Dweik, R.A., Kavuru, M. and Erzurum, S.C. (2000) Rapid loss of superoxide dismutase activity during antigen-induced asthmatic response. Lancet, 355, 624.

[25] Smith, L.J., Shamsuddin, M., Sporn, P.H.S., Denenberg, M. and Anderson, J. (1997) Reduced superoxide dismutase in lung cells of patients with asthma. Free Radical Biology \& Medicine, 22, 1301-1307. doi:10.1016/S0891-5849(96)00550-3

[26] Noor, R., Mittal, S. and Iqbal, J. (2002) Superoxide dismutase-Applications and relevance to human diseases. Medical Science Monitor, 8, 210-215. 
[27] Otto-Knapp, R., Jurgovsky, K., Schierhorn, K. and Kunkel, G. (2003) Antioxidative enzymes in human nasal mucosa after exposure to ozone. Possible role of GSTM1 deficiency. Inflammation Research, 52, 51-55. doi:10.1007/s000110300000

[28] Aguirre, F., Martin, I., Grinspon, D., et al. (1998) Oxidative damage, plasma antioxidant capacity, and glucemic control in elderly NIDDM patients. Free Radical Biology \& Medicine, 24, 580-585. doi:10.1016/S0891-5849(97)00293-1

[29] Mates, M.J., Jose, M.S., Cristina, P.G., Rafael, R., Lucia, O., Miguel, B. and Fransisca, M.S. (1999) Antioxidant enzymatic activities in human blood cells after an allergic reaction to pollen or house dust mite. Blood Cells, Molecules, and Diseases, 25, 103-109.

$$
\text { doi:10.1006/bcmd.1999.0234 }
$$

[30] Kalayci, O., Besler, T., Kilinç, K., Sekerel, B.E. and Saraçlar, Y. (2000) Serum levels of antioxidant vitamins (alpha tocopherol, beta carotene, and ascorbic acid) in children with bronchial asthma. The Turkish Journal of Pediatrics, 42, 17-21.

[31] Podoshin, L., Gertner, R. and Fradis, M. (1991) Treatment of perennial allergic rhinitis with ascorbic acid solution. Ear Nose Throat Journal, 70, 54-55.

[32] Robison, R. and Kumar, R. (2010) The effect of prenatal and postnatal dietary exposures on childhood development of atopic disease. Current Opinion in Allergy and Clinical Immunology, 10, 139-144. doi:10.1097/ACI.0b013e32833667a8 